\title{
Pharmacological treatments for neuropsychiatric symptoms of dementia in long-term care: a systematic review
}

\author{
Dallas P. Seitz, ${ }^{1}$ Sudeep S. Gill, ${ }^{2}$ Nathan Herrmann, ${ }^{3,4}$ Sarah Brisbin, \\ Mark J. Rapoport, ${ }^{3,4}$ Jenna Rines, ${ }^{1}$ Kimberley Wilson, ${ }^{5}$ Ken Le Clair ${ }^{1}$ \\ and David K. Conn ${ }^{3,6}$ \\ ${ }^{1}$ Department of Psychiatry, Queen's University, Kingston, Ontario, Canada \\ ${ }^{2}$ Division of Geriatric Medicine, Queen's University, Kingston, Ontario, Canada \\ ${ }^{3}$ Department of Psychiatry, University of Toronto, Toronto, Ontario, Canada \\ ${ }^{4}$ Department of Psychiatry, Sunnybrook Health Sciences Centre, Toronto, Ontario, Canada \\ ${ }^{5}$ Canadian Coalition for Seniors' Mental Health, Toronto, Ontario, Canada \\ ${ }^{6}$ Department of Psychiatry, Baycrest Centre, Toronto, Ontario, Canada
}

ABSTRACT

Background: Medications are frequently prescribed for neuropsychiatric symptoms (NPS) associated with dementia, although information on the efficacy and safety of medications for NPS specifically in long-term care (LTC) settings is limited. The objective of this study was to provide a current review of the efficacy and safety of pharmacological treatments for NPS in LTC.

Methods: We searched MEDLINE, EMBASE, PsychINFO, and the Cochrane Library for randomized controlled trials comparing medications with either placebo or other interventions in LTC. Study quality was described using the Cochrane collaboration risk of bias tool. The efficacy of medications was evaluated using NPS symptom rating scales. Safety was evaluated through rates of trial withdrawals, trial withdrawals due to adverse events, and mortality.

Results: A total of 29 studies met inclusion criteria. The most common medications evaluated in studies were atypical antipsychotics $(\mathrm{N}=15)$, typical antipsychotics $(\mathrm{N}=7)$, anticonvulsants $(\mathrm{N}=4)$, and cholinesterase inhibitors $(\mathrm{N}=3)$. Statistically significant improvements in NPS were noted in some studies evaluating risperidone, olanzapine, and single studies of aripiprazole, carbamazepine, estrogen, cyproterone, propranolol, and prazosin. Study quality was difficult to rate in many cases due to incomplete reporting of details. Some studies reported higher rates of trial withdrawals, adverse events, and mortality associated with medications.

Conclusions: We conclude that there is limited evidence to support the use of some atypical antipsychotics and other medications for NPS in LTC populations. However, the generally modest efficacy and risks of adverse events highlight the need for the development of safe and effective pharmacological and non-pharmacological interventions for this population.

Key words: dementia, Alzheimer, long-term care, pharmacological, medications

\section{Introduction}

Neuropsychiatric symptoms (NPS) associated with dementia are common in long-term care (LTC) settings with approximately $80 \%$ of individuals with dementia in LTC exhibiting NPS at any time (Zuidema et al., 2007; Seitz et al.,

Correspondence should be addressed to: Dr. Dallas Seitz, Geriatric Psychiatry Services, Providence Care - Mental Health Services, 752 King Street West, Kingston, Ontario, Canada, K7L 4X3. Telephone: 613-548-5567, ext: 5942; Fax: 613-540-6128. Email: seitzd@providencecare.ca Received 28 Feb 2012; revision requested 15 Apr 2012; revised version received 10 May 2012; accepted 30 Aug 2012. First published online 19 October 2012.
2010). Guidelines (Canadian Coalition for Seniors' Mental Health, 2006; Herrmann et al., 2007) and previous reviews (Sink et al., 2005) have emphasized the importance of comprehensive assessment to rule out pain (Cohen-Mansfield and Mintzer, 2005; Sink et al., 2005), delirium (Sink et al., 2005), and environmental or interpersonal factors (Sink et al., 2005) which may precipitate behaviors. Non-pharmacological interventions are usually recommended as first-line treatments for NPS. Unfortunately, knowledge of psychosocial interventions in LTC is low (Cohen-Mansfield and Jensen, 2008), access to services for these 
interventions is limited (Conn, 1992; Burns et al., 1993; Meeks, 1996; Reichman et al., 1998; Seitz et al., 2011), their effectiveness may be modest (Seitz et al., 2012), and patients may not cooperate with these interventions (Cohen-Mansfield et al., 2012). Therefore, there remains a potential role for medications in managing NPS in LTC.

Psychotropic medications are frequently prescribed in LTC (Gruber-Baldini et al., 2004; Pitkala et al., 2004; Selbaek et al., 2007). The estimated prevalence of the use of these medications among LTC residents with dementia is $25 \%-40 \%$ for antipsychotics (Pitkala et al., 2004; Rochon et al., 2007; Selbaek et al., 2008; Nijk et al., 2009; Larrayadieu et al., 2011; Snowdon et al., 2011), 25\%-30\% for antidepressants (Pitkala et al., 2004; Nijk et al., 2009; Snowdon et al., 2011), cognitive enhancers in $25 \%-30 \%$ (Seitz et al., 2009), and benzodiazepines in 15\%-30\% (Pitkala et al., 2004; Selbaek et al., 2008; Nijk et al., 2009; Snowdon et al., 2011). Systematic reviews and meta-analyses have indicated that some typical antipsychotics (Schneider et al., 1990; Lanctot et al., 1998), atypical antipsychotics (Ballard and Waite, 2006; Schneider et al., 2006b), and antidepressants (Seitz et al., 2011) may have benefits in treating certain NPS, although the magnitude of benefit may be limited and potentially outweighed by adverse events. Atypical antipsychotics, the most extensively studied and utilized medications for NPS, are also associated with serious adverse events such as death (Schneider et al., 2005; Wang et al., 2005; Gill et al., 2007) or stroke (Herrmann et al., 2004, Gill et al., 2005), as well as falls (Hien Le et al., 2005), sedation (Schneider et al., 2006a), and cognitive decline (Schneider et al., 2006a; Vigen et al., 2011). Although there has been a decline in the use of antipsychotics with dementia recently, these medications continue to be used frequently (Kales et al., 2011). The safety of other medications used to treat NPS in LTC has also been questioned (Huybrechts et al., 2011).

Although there are previous reviews on the use of psychotropic medications for the management of NPS (Schneider et al., 1990; 2006a; Borson and Raskind, 1997; Lanctot et al., 1998; Sutor et al., 2001; Kindermann et al., 2002; Snowden et al., 2003; Alexopoulos et al., 2005; Bharani and Snowden, 2005; Sink et al., 2005; Ballard and Howard, 2006; Kozman et al., 2006; Herrmann and Lanctot, 2007; Konavalov et al., 2007; Saddichha and Pandey, 2008; Ballard et al., 2009a; 2009b; Conn and Seitz, 2010; Gauthier et al., 2010), few have focused exclusively on studies conducted in LTC settings (Snowden et al., 2003; Bharani and Snowden, 2005). Residents of LTC facilities with dementia may be particularly susceptible to adverse events associated with psychotropics when compared with community or hospital-based populations. Controlled trials and observational studies of older adults with dementia have indicated that LTC residents have more advanced age, more severe cognitive impairment, higher rates of comorbidity (Schneider et al., 2006a; Gill et al., 2007; Rochon, 2008), and receive lower quality of routine and preventative care (Fahey et al., 2003) than outpatient or hospital populations. In addition, higher rates of mortality have been observed for LTC residents with dementia newly started on antipsychotics when compared with communitydwelling populations (Gill et al., 2007; Rochon et al., 2008). For these reasons, LTC residents may be particularly susceptible to mortality and other adverse events associated with psychotropic use which may have been underestimated in previous reviews which included both LTC and other populations within the same review. Also, some reviews have included both randomized and nonrandomized studies (Bharani and Snowden, 2005). Importantly, only a few previous reviews have assessed the quality of studies (Schneider et al., 2006a). Therefore, the objectives of this study were to provide a systematic review of randomized controlled trials (RCTs) for pharmacological treatments of NPS conducted specifically in LTC settings and evaluate the efficacy, and safety of treatments as well as the quality of studies.

\section{Methods}

\section{Search strategy}

Standard guidelines for conducting systematic reviews were used to guide the review process (Moher et al., 2009). We searched the electronic databases Medline, EMBASE, and PsychINFO (January 1980-February 2011), and the Cochrane Library using free text and medical subject headings to identify relevant articles (see Box 1, available as supplementary material attached to the electronic version of this paper at www.journals.cambridge.org/jid_IPG). Google Scholar was also searched for additional articles using key words and citation lists. Hand-searches of reference lists of retrieved articles, previous reviews, and guidelines (Canadian Coalition for Seniors' Mental Health, 2006) were used to supplement the electronic database search.

\section{Study selection}

The titles and abstracts of citations from electronic databases were independently reviewed by two study authors. Full-text articles were then reviewed 
for inclusion criteria. Randomized, parallel-group, controlled trials comparing any pharmacological intervention to placebo, another medication, or non-pharmacological interventions were included. We only included studies where NPS was the primary study outcome. We included studies reporting overall levels of NPS using composite measures of NPS on commonly utilized rating scales (e.g. Neuropsychiatric Inventory) or on specific measures of agitation, psychosis, or aggression. Studies that only evaluated depression or apathy in LTC residents with dementia were excluded. We excluded uncontrolled pre-post studies and crossover designs given the high-placebo response rate observed in some studies (Schneider et al., 2006a). Study populations had to be exclusively from LTC or where LTC residents formed the majority $(>50 \%)$ of participants. All Englishlanguage publications that provided sufficient detail for data extraction were included. Full-text articles were reviewed for inclusion criteria by two study authors with discrepancies resolved through discussion.

\section{Data extraction}

We extracted the following information from studies: dose of medication, number of participants, gender distribution, number and location of LTC facilities, dementia severity, method for diagnosing dementia, and study duration. We categorized studies according to pharmacological class. Baseline severity of NPS and change in NPS as reported on NPS rating scales (e.g. CohenMansfield Agitation Inventory) were recorded. For dichotomous outcomes (e.g. number of individuals with a treatment response), the number of individuals with the outcome was recorded. For studies that did not report a primary outcome, we selected the change in NPS symptom rating scale total score as measured at study endpoint as the primary measure of efficacy. Safety and tolerability outcomes included: rates of trial withdrawals due to any cause, trial withdrawals due to adverse events, and mortality. All data were extracted in duplicate by two study authors using a standard data extraction form and discrepancies were resolved through further discussion.

\section{Study quality}

The Cochrane collaboration risk of bias assessment tool was utilized to describe the potential risk of bias associated with various aspects of study design (Higgins and Green, 2008). This tool evaluates the following properties of studies: method of random sequence generation, concealment of allocation, blinding, incomplete outcome data, selective outcome reporting, and other potential sources of bias including sponsorship bias (i.e. whether the funding source could have led to a potential financial conflict of interest). Each item was rated as being potentially at low risk of bias ("Yes"), high risk of bias ("No"), or unclear. All items were rated in duplicate by two authors.

\section{Data synthesis}

Information on study characteristics, assessment of study quality, and efficacy and safety outcomes was summarized in tables. We summarized the effects of pharmacological interventions by medication class. The studies that reported on both antipsychotics and another active comparator were described in the non-antipsychotic category (e.g. studies comparing antipsychotics and cholinesterase inhibitors were described under the cholinesterase inhibitor section).

\section{Results}

\section{Study selection}

The flow of studies through the review process is summarized in Figure 1. A total of 8,342 citations were identified through searches of electronic databases and 315 full-text articles were retrieved and reviewed. From these articles, 29 studies were identified that met our inclusion criteria.

\section{Characteristics of included studies}

The 29 studies meeting inclusion criteria encompassed 19 studies of antipsychotics (Barnes et al., 1982; Cantillon et al., 1996; De Deyn et al., 1999; 2004; Katz et al., 1999; Street et al., 2000; Gaber et al., 2001; Brodaty et al., 2003; Fontaine et al., 2003; Ballard et al., 2005; Mintzer et al., 2006; 2007; Tariot et al., 2006; Verhey et al., 2006; Holmes et al., 2007; Huertas et al., 2007; Zhong et al., 2007; Streim et al., 2008; Rappaport et al., 2009) (15 studies of atypical antipsychotics (De Deyn et al., 1999; 2004; Katz et al., 1999; Street et al., 2000; Brodaty et al., 2003; Fontaine et al., 2003; Ballard et al., 2005; Mintzer et al., 2006; 2007; Tariot et al., 2006; Verhey et al., 2006; Holmes et al., 2007; Zhong et al., 2007; Streim et al., 2008; Rappaport et al., 2009) and seven of typical antipsychotics (Barnes et al., 1982; Cantillon et al., 1996; De Deyn et al., 1999; Gaber et al., 2001; Tariot et al., 2006; Verhey et al., 2006; Huertas et al., 2007)), three studies of cholinesterase inhibitors (Tariot et al., 2001; Ballard et al., 2005; Holmes et al., 2007), four studies of anticonvulsants (Tariot et al., 1998; 2005; Porsteinsson et al., 2001; Sommer et al., 2009), one study of antidepressants 


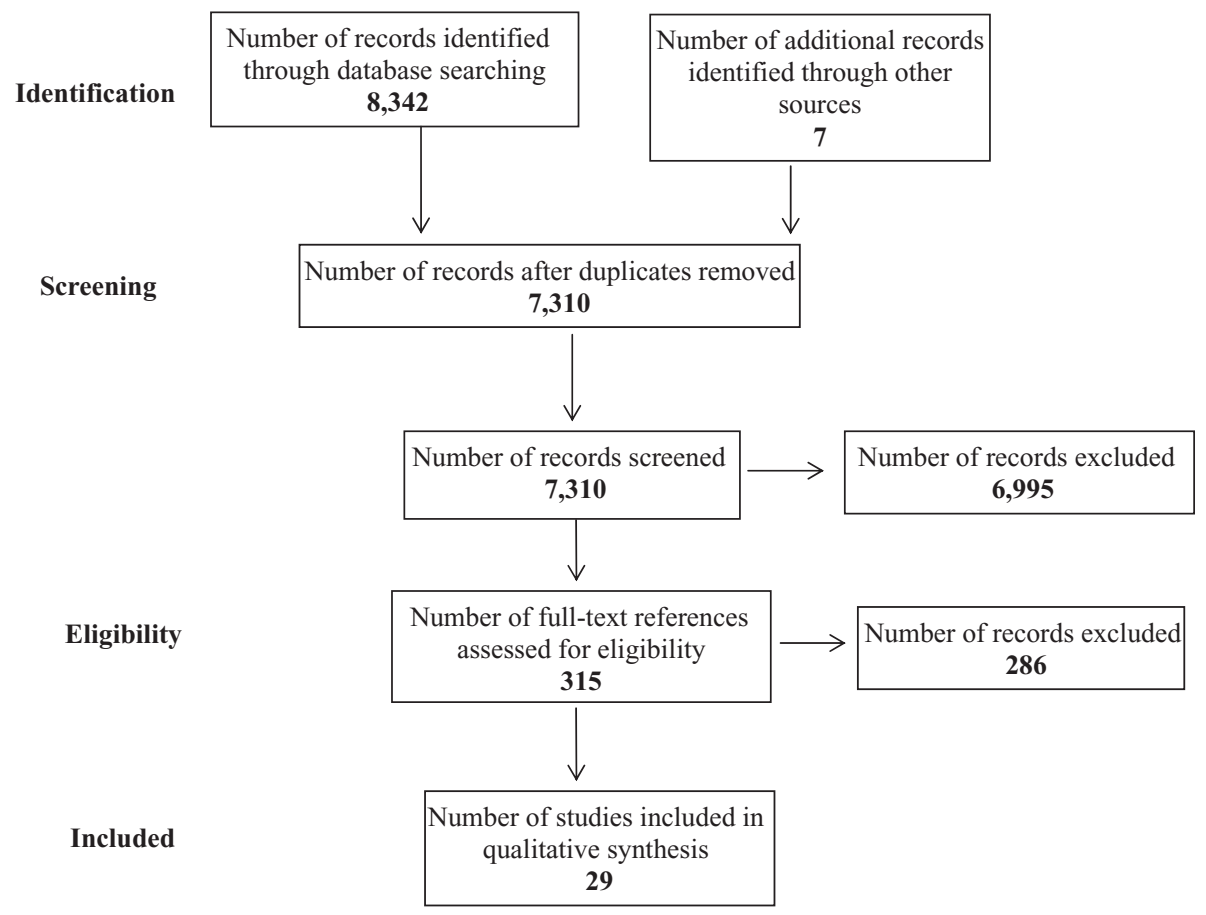

Figure 1. Flow of studies through the review process.

(Gaber et al., 2001), and seven studies evaluating medications from other classes (Cantillon et al., 1996; Kyomen et al., 1999; Hall et al., 2005; Peskind et al., 2005; Huertas et al., 2007; Gehrman et al., 2009; Wang et al., 2009) (Table 1). Of these studies, 20 were placebo-controlled (Barnes et al., 1982; Tariot et al., 1998; 2001; 2005; De Deyn et al., 1999; 2004; Katz et al., 1999; Kyomen et al., 1999; Street et al., 2000; Porsteinsson et al., 2001; Brodaty et al., 2003; Ballard et al., 2005; Hall et al., 2005; Peskind et al., 2005; Mintzer et al., 2006; 2007; Tariot et al., 2006; Zhong et al., 2007; Streim et al., 2008; Gehrman et al., 2009; Rappaport et al., 2009; Sommer et al., 2009; Wang et al., 2009), and 11 compared two medications within the same trial (Barnes et al., 1982; Cantillon et al., 1996; De Deyn et al., 1999; Gaber et al., 2001; Fontaine et al., 2003; Ballard et al., 2005; Tariot et al., 2006; Verhey et al., 2006; Holmes et al., 2007; Huertas et al., 2007). All of the studies used oral formulations of medications except for one trial that utilized intramuscular aripiprazole (Rappaport et al., 2009) and one study of transdermal estrogen (Hall et al., 2005). A total of 4,954 individuals were included with a median study sample size of 76 (range $=14-625$ participants per trial). The median age of participants in studies was 83 years and $71 \%$ were women in studies reporting the gender distribution. Most study participants had moderate to severe dementia with average Mini-Mental State Examination (MMSE) scores of between 5 and 14 . The median trial duration was 56 days (range $=$
1-90 days). A variety of outcome measures were reported in studies including composite measures of NPS (Barnes et al., 1982; Cantillon et al., 1996; Tariot et al., 1998; 2001; 2005; 2006; De Deyn et al., 1999; 2004; Katz et al., 1999; Street et al., 2000; Porsteinsson et al., 2001; Fontaine et al., 2003; Peskind et al., 2005; Gehrman et al., 2009; Sommer et al., 2009; Wang et al., 2009), agitation (Gaber et al., 2001; Ballard et al., 2005; Verhey et al., 2006; Holmes et al., 2007; Zhong et al., 2007; Rappaport et al., 2009,), aggression (Kyomen et al., 1999; Brodaty et al., 2003; Hall et al., 2005; Huertas et al., 2007), or psychosis (Mintzer et al., 2006; 2007; Streim et al., 2008).

\section{Efficacy of interventions on neuropsychiatric symptoms of dementia}

The efficacy of pharmacological interventions for NPS is summarized in Table 1.

\section{ANTIPSYCHOTICS}

The 15 studies of atypical antipsychotics involved risperidone $(\mathrm{N}=6)$, olanzapine $(\mathrm{N}=4)$, quetiapine $(\mathrm{N}=3)$, and aripiprazole $(\mathrm{N}=3)$. Statistically significant results on change in NPS scores compared with placebo were noted in two studies of risperidone (Katz et al., 1999; Brodaty et al., 2003), two studies of olanzapine (Street et al., 2000; De Deyn et al., 2004), and one study of aripiprazole (Mintzer et al., 2007). One study comparing risperidone and olanzapine found no 
Table 1. Included studies of pharmacological interventions for long-term care residents with dementia

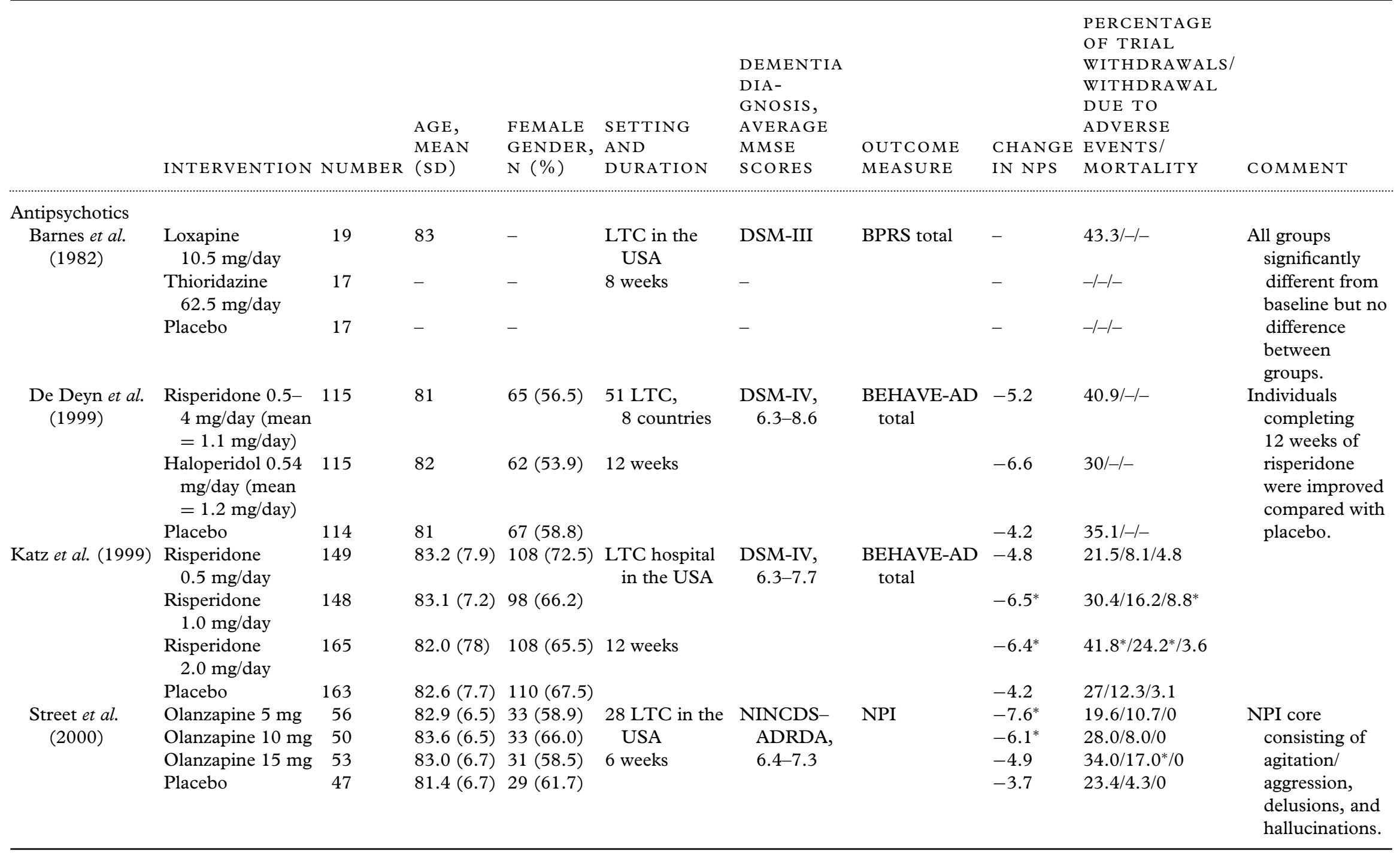




\begin{tabular}{|c|c|c|c|c|c|c|c|c|c|c|}
\hline & INTERVENTION & NUMBER & $\begin{array}{l}\text { AGE, } \\
\text { MEAN } \\
(\mathrm{SD})\end{array}$ & $\begin{array}{l}\text { FEMALE } \\
\text { GENDER, } \\
\text { N }(\%)\end{array}$ & $\begin{array}{l}\text { SETTING } \\
\text { AND } \\
\text { DURATION }\end{array}$ & $\begin{array}{l}\text { DEMENTIA } \\
\text { DIAGNOSIS, } \\
\text { AVERAGE } \\
\text { MMSE } \\
\text { SCORES }\end{array}$ & $\begin{array}{l}\text { OUTCOME } \\
\text { MEASURE }\end{array}$ & $\begin{array}{l}\text { CHANGE } \\
\text { IN NPS }\end{array}$ & $\begin{array}{l}\text { PERCENTAGE } \\
\text { OF TRIAL } \\
\text { WITHDRAWALS/ } \\
\text { WITHDRAWAL } \\
\text { DUE TO } \\
\text { ADVERSE } \\
\text { EVENTS/ } \\
\text { MORTALITY }\end{array}$ & COMMENT \\
\hline $\begin{array}{l}\text { Brodaty et al. } \\
\quad(2003)\end{array}$ & $\begin{array}{l}\text { Risperidone } 0.5- \\
2 \mathrm{mg} / \text { day (mean } \\
=0.95 \mathrm{mg} / \text { day) } \\
\text { Placebo }\end{array}$ & $\begin{array}{l}153 \\
156\end{array}$ & $83.2(0.5)$ & $109(71)$ & $\begin{array}{r}14 \text { LTC sites in } \\
\text { Australia and } \\
\text { New Zealand }\end{array}$ & $\begin{array}{l}\text { DSM-IV, AD, } \\
\text { vascular, } \\
\text { mixed } \\
5.1-5.8\end{array}$ & $\begin{array}{l}\text { CMAI-total } \\
\text { aggression }\end{array}$ & $-7.5^{*}$ & $32.9 / 8.2 / 2.4$ & \multirow{11}{*}{$\begin{array}{l}\text { BEHAVE-AD } \\
\text { score also } \\
\text { improved with } \\
\text { risperidone. } \\
\text { Both groups } \\
\text { improved, no } \\
\text { difference } \\
\text { between } \\
\text { groups. }\end{array}$} \\
\hline \multirow[t]{2}{*}{$\begin{array}{l}\text { Fontaine et al. } \\
\quad(2003)\end{array}$} & $\begin{array}{l}\text { Olanzapine } \\
2.5-10 \mathrm{mg} \\
\text { (mean } \\
6.6 \mathrm{mg} / \text { day) }\end{array}$ & 20 & $83.3(5.7)$ & $12(60)$ & $\begin{array}{l}\text { LTC in the } \\
\text { USA }\end{array}$ & $\begin{array}{l}\text { DSM-IV, } \\
\text { dementia }\end{array}$ & NPI & -15 & $20 / 20 / 0$ & \\
\hline & $\begin{array}{l}\text { Risperidone 0.5- } \\
2 \mathrm{mg} \text { (mean } \\
1.5 \mathrm{mg} / \text { day) }\end{array}$ & 19 & $83.0(9.4)$ & $14(74)$ & 12 weeks & $7.2-9.3$ & & -23.6 & $32.9 / 8.2 / 2.4$ & \\
\hline \multirow[t]{3}{*}{$\begin{array}{l}\text { De Deyn et al. } \\
\quad(2004)\end{array}$} & $\begin{array}{l}\text { Olanzapine } \\
1 \mathrm{mg} / \text { day } \\
\text { Olanzapine } \\
2.5 \mathrm{mg} / \text { day }\end{array}$ & $\begin{array}{l}128 \\
134\end{array}$ & $\begin{array}{l}76.6(10.4) \\
-\end{array}$ & $489(75)$ & \multirow{3}{*}{$\begin{array}{l}\text { LTC or } \\
\text { continuing- } \\
\text { care hospitals } \\
\text { in Europe, } \\
\text { Australia, } \\
\text { Israel, } \\
\text { Lebanon, } \\
\text { South Africa } \\
10 \text { weeks }\end{array}$} & \multirow{3}{*}{$\begin{array}{l}\text { NINCDS- } \\
\text { ADRDA, } \\
\text { DSM-IV- } \\
\text { TR, AD } \\
13.7(5.1)\end{array}$} & \multirow[t]{3}{*}{ NPI-NH total } & $\begin{array}{l}-14.8 \\
-15.7\end{array}$ & & \\
\hline & $\begin{array}{l}\text { Olanzapine } \\
5 \mathrm{mg} / \text { day }\end{array}$ & 123 & - & - & & & & -16.3 & & \\
\hline & $\begin{array}{l}\text { Olanzapine } \\
7.5 \mathrm{mg} / \text { day } \\
\text { Placebo }\end{array}$ & 128 & - & - & & & & $\begin{array}{l}-17.7^{*} \\
-13.7\end{array}$ & & \\
\hline \multirow[t]{2}{*}{$\begin{array}{l}\text { Mintzer et al. } \\
\quad(2006)\end{array}$} & $\begin{array}{l}\text { Risperidone } \\
0.5-1.5 \mathrm{mg} \\
\text { daily (mean }= \\
1.0 \mathrm{mg} / \text { day })\end{array}$ & 202 & $83.4(7.0)$ & $152(75.2)$ & \multirow[t]{2}{*}{$\begin{array}{l}44 \text { LTC } \\
8 \text { weeks }\end{array}$} & \multirow[t]{2}{*}{ AD 13.1-13.2 } & \multirow[t]{2}{*}{$\begin{array}{c}\text { BEHAVE-AD } \\
\text { Psychosis }\end{array}$} & -2.9 & $25.5 / 10.6 / 0.8$ & \\
\hline & Placebo & 214 & $83.3(7.43)$ & $163(76.2)$ & & & & -2.3 & $24.8 / 10.1 / 0$ & \\
\hline \multirow[t]{3}{*}{$\begin{array}{l}\text { Tariot et al. } \\
\text { (2006) }\end{array}$} & $\begin{array}{l}\text { Quetiapine } \\
100 \mathrm{mg} / \text { day }\end{array}$ & 91 & $81.9(6.9)$ & $66(73)$ & \multirow[t]{3}{*}{$\begin{array}{l}47 \text { LTC in the } \\
\text { USA } 10 \text { weeks }\end{array}$} & \multirow{3}{*}{$\begin{array}{l}\text { DSM-IV, } \\
\text { NINCDS- } \\
\text { ADRDA, } \\
\text { AD, } \\
\text { vascular, } \\
\text { alcohol } \\
12.4-13.2\end{array}$} & \multirow[t]{3}{*}{ BPRS total } & -9.1 & $31.9 / 11.0 / 0$ & \\
\hline & $\begin{array}{l}\text { Haloperidol } \\
2.5 \mathrm{mg} / \text { day }\end{array}$ & 94 & $83.5(6.1)$ & $63(67)$ & & & & -7.1 & $41.5 / 18.1 / 1.1$ & \\
\hline & Placebo & 99 & $83.9(6.7)$ & $79(80)$ & & & & -6.7 & $36.4 / 13.1 / 0$ & \\
\hline
\end{tabular}




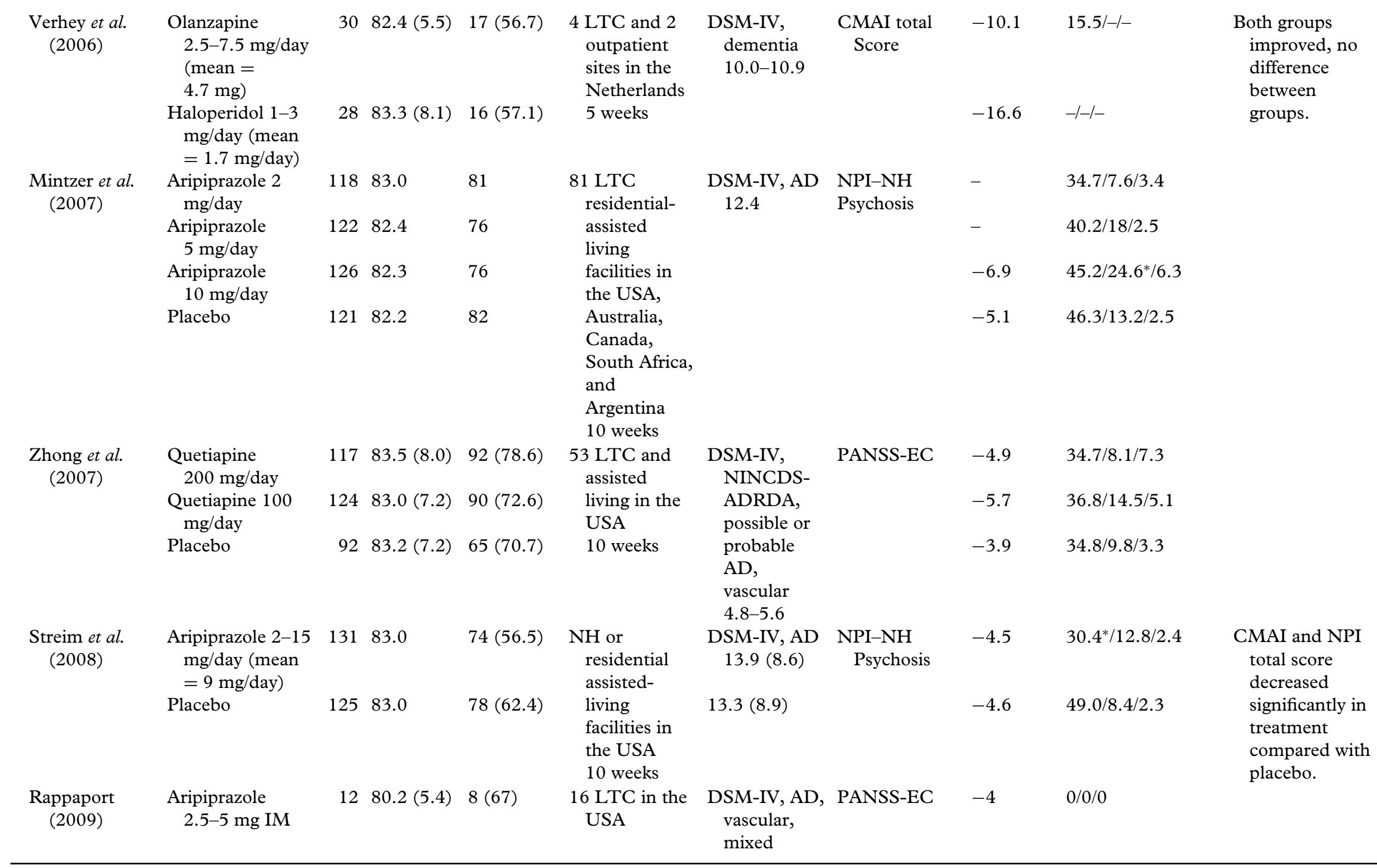




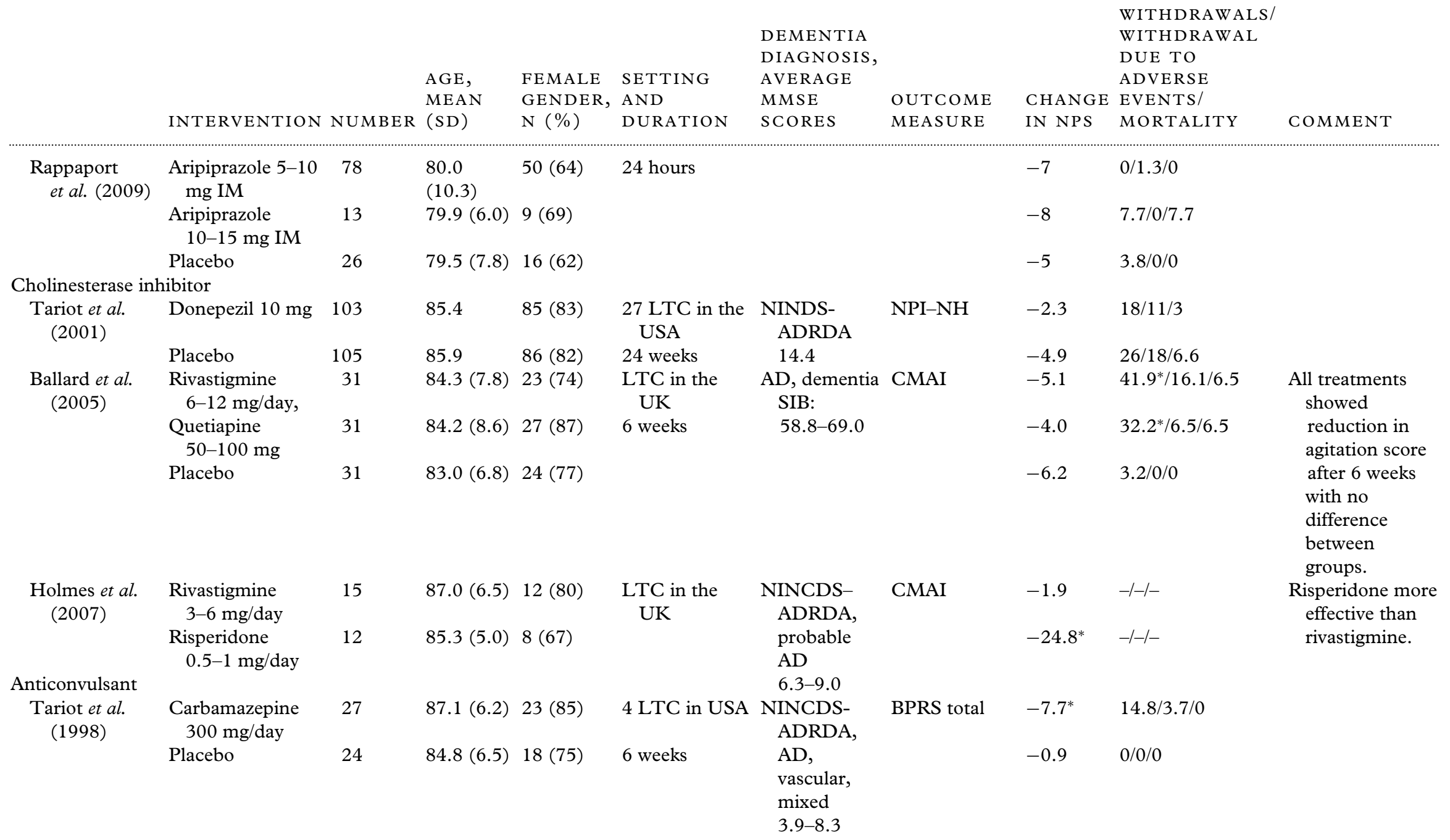




\begin{tabular}{|c|c|c|c|c|c|c|c|c|c|c|}
\hline $\begin{array}{l}\text { Porsteinsson } \\
\text { et al. }(2001)\end{array}$ & $\begin{array}{l}\text { Divalproex } \\
\text { sodium } \\
375 \mathrm{mg} / \text { day } \\
\text { Placebo }\end{array}$ & 28 & $85.3(8.1)$ & $17(61)$ & $\begin{array}{l}7 \text { LTC in the } \\
\text { USA }\end{array}$ & $\begin{array}{l}\text { DSM-IV, } \\
\text { NINCDS- } \\
\text { ADRDA, } \\
\text { AD, } \\
\text { vascular, } \\
\text { mixed } \\
6.7-7.0\end{array}$ & BPRS total & -6.9 & $12.5 / 12.5 / 0$ & $\begin{array}{l}\text { No significant } \\
\text { difference } \\
\text { reported on } \\
\text { CMAI. }\end{array}$ \\
\hline \multirow[t]{2}{*}{$\begin{array}{l}\text { Tariot et al. } \\
\quad(2005)\end{array}$} & $\begin{array}{l}\text { Divalproex } \\
\text { sodium } 800 \\
\text { mg/day }\end{array}$ & 75 & $84.2(6.6)$ & $48(63)$ & $\begin{array}{l}\text { LTC in the } \\
\text { USA }\end{array}$ & $\begin{array}{l}\text { NINCDS- } \\
\text { ADRDA, } \\
\text { probable }\end{array}$ & BPRS total & -4.2 & $14.7 / 6.6 / 1.3$ & \\
\hline & Placebo & 78 & $83.9(5.9)$ & $57(73)$ & 6 weeks & $\begin{array}{l}\mathrm{AD} \\
10.5-10.8\end{array}$ & & -5.1 & $17.9 / 6.4 / 0$ & \\
\hline \multirow[t]{2}{*}{$\begin{array}{l}\text { Sommer et al. } \\
\text { (2009) }\end{array}$} & $\begin{array}{l}\text { Oxcarbazepine } \\
\text { 300-900 } \\
\text { mg/day }\end{array}$ & 52 & 83 & $35(67.3)$ & $\begin{array}{l}35 \text { LTC in } \\
\text { Norway }\end{array}$ & \multirow[t]{2}{*}{$\begin{array}{l}\mathrm{ICD}-10, \mathrm{AD}, \\
\text { vascular } \\
5.4-6.2\end{array}$} & \multirow[t]{2}{*}{ NPI-NH } & - & $28.8^{*} / 21.1 / 0$ & \multirow{2}{*}{$\begin{array}{l}\text { Change in score } \\
\text { not reported } \\
\text { but difference } \\
\text { not statistically } \\
\text { significant. }\end{array}$} \\
\hline & Placebo & 51 & 84 & $38(74.5)$ & 8 weeks & & & - & $9.8 / 7.9 / 0$ & \\
\hline \multirow{3}{*}{$\begin{array}{l}\text { Antidepressant } \\
\text { Gaber et al. } \\
\text { (2001) }\end{array}$} & & & & & & & & & & \\
\hline & $\begin{array}{l}\text { Sertraline } \\
25-50 \mathrm{mg} / \text { day }\end{array}$ & 13 & $81.5(6.7)$ & - & $\begin{array}{l}\text { Institutionalized } \\
\text { in Italy }\end{array}$ & $\begin{array}{l}\text { DSM-IV, } \\
\text { dementia }\end{array}$ & CMAI & -13 & $-1-1-$ & \multirow{7}{*}{$\begin{array}{l}\text { No significant } \\
\text { differences } \\
\text { from baseline } \\
\text { to } 10 \text { weeks in } \\
\text { either group. }\end{array}$} \\
\hline & $\begin{array}{l}\text { Haloperidol } \\
\qquad 1-2 \mathrm{mg} / \text { day }\end{array}$ & 10 & - & - & 10 weeks & $\begin{array}{l}- \\
-\end{array}$ & & -10 & $-1-/-$ & \\
\hline \multicolumn{10}{|l|}{ Other } & \\
\hline \multirow[t]{2}{*}{$\begin{array}{l}\text { Cantillon et al. } \\
\quad(1996)\end{array}$} & $\begin{array}{l}\text { Buspirone } 5 \mathrm{mg} \\
\text { TID }\end{array}$ & 12 & $78.8(5.1)$ & $8(66.7)$ & LTC in USA & \multirow{2}{*}{$\begin{array}{l}\text { NINCDS- } \\
\text { ADRDA, } \\
\text { probable } \\
\text { AD 2.5-2.6 }\end{array}$} & \multirow[t]{2}{*}{ BPRS total } & \multirow[t]{2}{*}{-6.7} & $-/-1-$ & \\
\hline & $\begin{array}{l}\text { Haloperidol } \\
0.5 \mathrm{mg} \text { TID }\end{array}$ & 14 & $79.6(4.9)$ & $9(64.3)$ & 10 weeks & & & & $-/-1-$ & \\
\hline \multirow[t]{2}{*}{$\begin{array}{l}\text { Kyomen et al. } \\
\quad(1999)\end{array}$} & $\begin{array}{l}\text { Estrogen } \\
\quad 0.625-2.5 \mathrm{mg}\end{array}$ & 8 & $81.0(3.7)$ & $7(87.5)$ & LTC in USA & $\begin{array}{l}\text { DSM-III-R, } \\
\text { dementia }\end{array}$ & OAS & $+4.7^{*}$ & $0 / 0 / 0$ & \\
\hline & Placebo & 6 & $87.8(8.27)$ & $5(83.3)$ & 4 weeks & $4.1-5.5$ & & +2.1 & $16.7 / 0 / 0$ & \\
\hline \multirow[t]{2}{*}{$\begin{array}{l}\text { Hall et al. } \\
\text { (2005) }\end{array}$} & $\begin{array}{l}\text { Estrogen } \\
\text { transdermal } \\
\text { patch, 50-100 } \\
\text { mcg/day }\end{array}$ & 13 & $78.1(6.2)$ & $0(0)$ & $\begin{array}{l}\text { LTC and psych } \\
\text { inpatient } \\
\text { ward, } \\
\text { Australia }\end{array}$ & $\begin{array}{l}\text { DSM-IV, } \\
\text { dementia } \\
2.6-5.4\end{array}$ & RAGE & $\sim 2.5$ & $-/-/ 0$ & \multirow[t]{2}{*}{$\begin{array}{l}\text { Results reported } \\
\text { as "no } \\
\text { significant } \\
\text { difference" on } \\
\text { RAGE. }\end{array}$} \\
\hline & Placebo & 14 & $78.8(9.6)$ & $0(0)$ & 8 weeks & & & $\sim 1$ & $-1-/ 0$ & \\
\hline
\end{tabular}




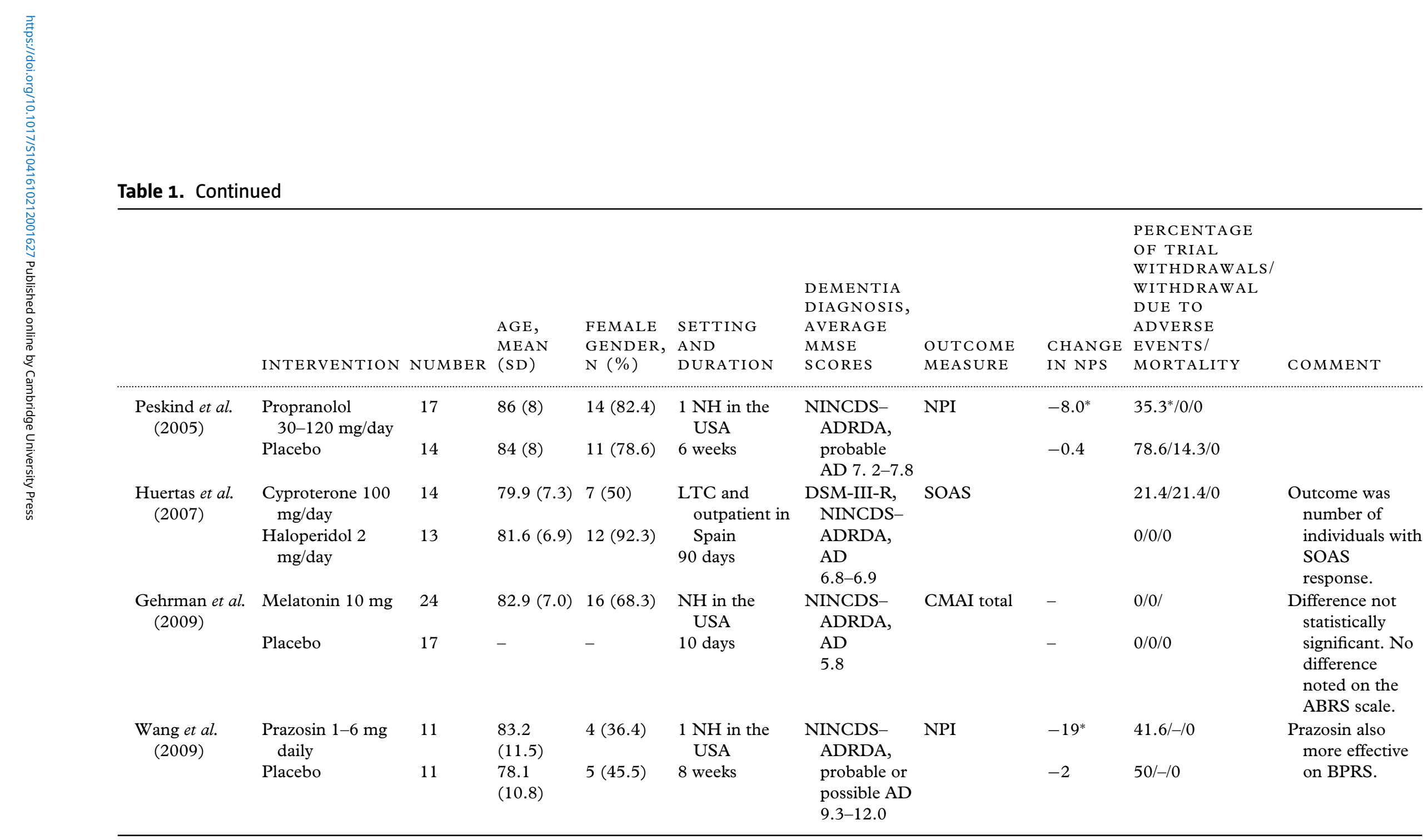

${ }^{*} \mathrm{p}<0.05$ when compared with placebo or other comparator medication in the study; $-=$ not reported.

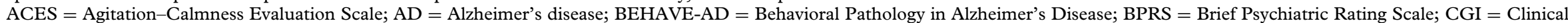

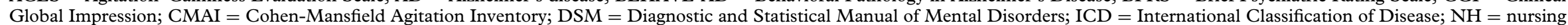

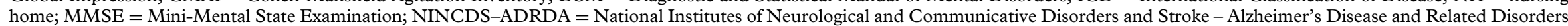

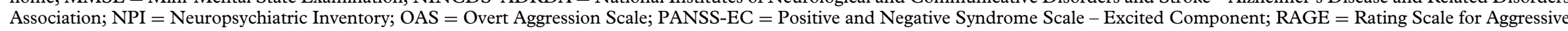
Behavior in the Elderly; SIB = Severe Impairment Battery; SOAS = Staff Observation Aggression Scale 
statistically significant difference between the two groups (Fontaine et al., 2003). Olanzapine and haloperidol were both associated with reductions in agitation and NPS with no significant differences between groups (Verhey et al., 2006). Risperidone was associated with greater reductions in agitation when compared with rivastigmine in one study (Holmes et al., 2007). One study also found no significant differences when either quetiapine or rivastigmine was compared with placebo (Ballard et al., 2005). A trial of quetiapine, haloperidol, and placebo found no difference between either of the two active treatment groups and placebo in measures of NPS (Tariot et al., 2006). A single trial compared the typical antipsychotics loxapine, thioridazine, and placebo and found no benefit for either medication over placebo (Barnes et al., 1982).

Eight studies reported change in NPS using dichotomized outcomes. Risperidone was associated with overall clinical improvement in NPS when compared with placebo in two studies (Brodaty et al., 2003; Mintzer et al., 2006) and significant reduction in NPS in a second study (Katz et al., 1999). However, a third study did not find any difference in response rates for risperidone compared with either haloperidol or placebo (De Deyn et al., 1999). Olanzapine at doses of 5 and $10 \mathrm{mg}$ daily were more likely to produce significant reductions in NPS when compared with placebo, although the $15 \mathrm{mg}$ dose was not better than placebo (Street et al., 2000). Aripiprazole was associated with a greater response rate than placebo in one study (Streim et al., 2008), while a second study did not find any difference in response (Mintzer et al., 2007). Quetiapine at $200 \mathrm{mg}$ daily was found to be associated with a higher proportion of individuals with significant global improvement than placebo in one study, while $100 \mathrm{mg}$ was not associated with significant benefit (Zhong et al., 2007).

\section{CHOLINESTERASE INHIBITORS}

One study of donepezil found no benefit for the medication when compared with placebo on measures of NPS (Tariot et al., 2001). Two studies evaluated the cholinesterase inhibitor rivastigmine (Ballard et al., 2005; Holmes et al., 2007), with there being no benefit for rivastigmine when compared with placebo (Ballard et al., 2005), or the atypical antipsychotics quetiapine (Ballard et al., 2005) or risperidone (Holmes et al., 2007).

\section{ANTICONVULSANTS}

Of the four placebo-controlled studies involving anticonvulsants, one evaluated carbamazepine (Tariot et al., 1998), two examined divalproex sodium (Porsteinsson et al., 2001; Tariot et al., 2005), and one study examined oxcarbazepine
(Sommer et al., 2009). Only carbamazepine was associated with a statistically significant reduction in NPS symptoms (Tariot et al., 1998) while the other studies showed no benefit for other anticonvulsants compared with placebo (Porsteinsson et al., 2001; Tariot et al., 2005; Sommer et al., 2009).

\section{ANTIDEPRESSANTS}

A single small study compared sertraline with haloperidol on NPS and found that both groups had a non-significant reduction in NPS with no difference between groups (Gaber et al., 2001).

\section{OTHER MEDICATIONS}

A study comparing buspirone and haloperidol found no significant difference between the two groups on symptoms of NPS (Cantillon et al., 1996). Two placebo-controlled studies evaluated the effects of estrogen therapy on NPS, one with oral estrogen (Kyomen et al., 1999) and a second with a transdermal estrogen patch (Hall et al., 2005), with only the study in which estrogen was administered orally demonstrating benefit over placebo. A single trial of the androgen antagonist cyproterone acetate compared with haloperidol and found that cyproterone was associated with greater improvement in NPS (Huertas et al., 2007). A placebo-controlled trial of the $\beta$-adrenergic antagonist propranolol demonstrated improvement in NPS symptoms scores and global improvement in NPS (Peskind et al., 2005). One study of the $\alpha-1$ adrenergic antagonist prazosin demonstrated benefits on NPS when compared with placebo (Wang et al., 2009). A placebo-controlled study of melatonin did not demonstrate any benefit for NPS (Gehrman et al., 2009).

\section{Safety and tolerability}

A total of 24 studies reported on trial withdrawals due to any cause (Tariot et al., 1998; 2001; 2005; 2006; De Deyn et al., 1999; 2004; Katz et al., 1999; Kyomen et al., 1999; Street et al., 2000; Porsteinsson et al., 2001; Brodaty et al., 2003; Fontaine et al., 2003; Ballard et al., 2005; Peskind et al., 2005; Mintzer et al., 2006; 2007; Huertas et al., 2007; Streim et al., 2008; Gehrman et al., 2009; Rappaport et al., 2009; Sommer et al., 2009; Wang et al., 2009), 21 studies reported on trial withdrawals due to adverse events (Tariot et al., 1998; 2001; 2005; 2006; Katz et al., 1999; Kyomen et al., 1999; Street et al., 2000; Porsteinsson et al., 2001; Brodaty et al., 2003; Fontaine et al., 2003; De Deyn et al., 2004; Ballard et al., 2005; Peskind et al., 2005; Mintzer et al., 2006; 2007; Huertas et al., 2007; Zhong et al., 2007; Streim et al., 2008; Gehrman et al., 2009; Rappaport et al., 2009; Sommer et al., 2009), and 23 studies reported 
mortality rates (Tariot et al., 1998; 2001; 2005; 2006; Katz et al., 1999; Kyomen et al., 1999; Street et al., 2000; Porsteinsson et al., 2001; Brodaty et al., 2003; Fontaine et al., 2003; De Deyn et al., 2004; Ballard et al., 2005; Hall et al., 2005; Peskind et al., 2005; Mintzer et al., 2006; 2007; Huertas et al., 2007; Zhong et al., 2007; Streim et al., 2008; Gehrman et al., 2009; Rappaport et al., 2009; Sommer et al., 2009; Wang et al., 2009) (Table 1). Trial withdrawals due to any cause or adverse events were common in many studies. One risperidone trial found that the $2 \mathrm{mg}$ dose was associated with higher rates of overall trial withdrawals and trial withdrawals due to adverse events compared with placebo, while mortality was higher with $1 \mathrm{mg}$ daily when compared with placebo (Katz et al., 1999). Olanzapine at $15 \mathrm{mg}$ daily was associated with higher rates of withdrawal due to adverse events although lower doses were not significantly different from placebo (Street et al., 2000). Only the $10 \mathrm{mg}$ dose of aripiprazole was associated with an increased risk of adverse events when compared with placebo in one study (Mintzer et al., 2007), while a second of aripiprazole found that overall rates of trial withdrawal were higher with aripiprazole (Streim et al., 2008). Both quetiapine and rivastigmine were associated with higher rates of withdrawal than placebo in one study (Ballard et al., 2005) as was oxcarbazepine when compared with placebo (Sommer et al., 2009). One study of propranolol found lower rates of trial withdrawals associated with drug treatment when compared with placebo (Peskind et al., 2005).

\section{Quality of studies}

In general, most studies were rated as being at low or unclear risk of bias due to various aspects related to study design (Table 2). Only one study was rated as being at low risk of bias on all the risk of bias items (Ballard et al., 2005). For the assessment of potential risk of bias associated with the study sponsor, 14 studies were funded by pharmaceutical companies, including 12 studies sponsored by the manufacturers of atypical antipsychotics (De Deyn et al., 1999; 2004; Katz et al., 1999; Street et al., 2000; Brodaty et al., 2003; Fontaine et al., 2003; Mintzer et al., 2006; 2007; Tariot et al., 2006; Zhong et al., 2007; Streim et al., 2008; Rappaport et al., 2009), one study of typical antipsychotics (Barnes et al., 1982), and one study of cholinesterase inhibitors (Tariot et al., 2001).

\section{Discussion}

Our review identified a number of RCTs evaluating a variety of medications for the management of NPS in LTC settings. Overall, the most frequently studied class of medications was atypical antipsychotics. There is some evidence to support the efficacy of the atypical antipsychotics risperidone, olanzapine, and aripiprazole when compared with placebo on change in NPS symptom scores. There were additional single small positive studies with carbamazepine, estrogen, cyproterone acetate, propranolol, and prazosin. The effects of medications tended to be clinically modest and only a few studies reported on the rates of clinically significant outcomes such as symptom remission. Some medications may be effective in reducing overall levels of NPS and specific NPS including agitation and aggression. The risk of bias for these studies varied, although many studies had some potentially important methodological limitations. Trial withdrawals, adverse events, and mortality were relatively common outcomes in many studies. Importantly, there were no studies comparing pharmacological agents to non-pharmacological approaches and a limited number of studies directly comparing different pharmacological agents.

The findings of our review of pharmacological treatments for NPS in LTC are consistent with previous broader reviews of antipsychotics and other medications for the treatment of NPS (Schneider et al., 1990; 2006a; Borson and Raskind, 1997; Lanctot et al., 1998; Sutor et al., 2001; Kindermann et al., 2002; Snowden et al., 2003; Alexopoulos et al., 2005; Sink et al., 2005; Ballard and Howard, 2006; Kozman et al., 2006; Herrmann and Lanctot, 2007; Konavalov et al., 2007; Saddichha and Pandey, 2008; Ballard et al., 2009a; 2009b; Conn and Seitz, 2010). The atypical antipsychotics (in particular risperidone, olanzapine, and aripiprazole) appear to have the most extensive evidence in favor of their use for NPS, although even this evidence is limited to a relatively small number of studies. There was only one study that directly compared two atypical antipsychotics with no statistically significant difference in NPS outcomes when comparing risperidone with olanzapine (Fontaine et al., 2003). Results from a large RCT comparing olanzapine, risperidone, quetiapine, and placebo for outpatients with Alzheimer's disease found that the primary outcome of time to discontinuation of treatment due to any cause did not differ between any of the three active treatment groups compared with placebo. However, time to discontinuation due to lack of efficacy favored both risperidone and olanzapine in this study (Schneider et al., 2006b). While most studies evaluated the effects of atypical antipsychotics on overall change in NPS, they appear to be most effective in reducing particular symptoms such as hostility, anger, 
Table 2. Risk of bias assessment for pharmacological treatment of neuropsychiatric symptoms of dementia

\begin{tabular}{|c|c|c|c|c|c|c|}
\hline & $\begin{array}{l}\text { SEQUENCE } \\
\text { GENERATION }\end{array}$ & $\begin{array}{l}\text { ALLOCATION } \\
\text { CONCEALMENT }\end{array}$ & BLINDING & $\begin{array}{l}\text { INCOMPLETE } \\
\text { OUTCOME } \\
\text { DATA }\end{array}$ & $\begin{array}{l}\text { SELECTIVE } \\
\text { OUTCOME } \\
\text { REPORTING }\end{array}$ & $\begin{array}{l}\text { OTHER - } \\
\text { FUNDING } \\
\text { SOURCE }\end{array}$ \\
\hline \multicolumn{7}{|l|}{ Antipsychotic } \\
\hline Barnes et al. (1982) & Unclear & Unclear & Unclear & Yes & Yes & No \\
\hline De Deyn et al. (1999) & Yes & Yes & Unclear & Yes & Yes & No \\
\hline Katz et al. (1999) & Yes & Unclear & Yes & Unclear & Yes & No \\
\hline Street et al. (2000) & Unclear & Unclear & Unclear & Yes & Yes & No \\
\hline Brodaty et al. (2003) & Yes & Unclear & Yes & Yes & Yes & No \\
\hline Fontaine et al. (2003) & Unclear & Unclear & Unclear & No & Yes & No \\
\hline De Deyn et al. (2004) & Unclear & Unclear & Unclear & Yes & Yes & No \\
\hline Mintzer et al. (2006) & Unclear & Yes & Unclear & Unclear & Yes & No \\
\hline Tariot et al. (2006) & Unclear & Unclear & Unclear & Yes & Yes & No \\
\hline Verhey et al. (2006) & Unclear & Unclear & Unclear & Yes & Yes & Yes \\
\hline Mintzer et al. (2007) & Unclear & Unclear & Unclear & Yes & Yes & No \\
\hline Zhong et al. (2007) & Yes & Unclear & Unclear & Yes & Yes & No \\
\hline Streim et al. (2008) & Unclear & Unclear & Unclear & Yes & Yes & No \\
\hline Rappaport et al. (2009) & Unclear & Unclear & Unclear & Yes & No & No \\
\hline \multicolumn{7}{|l|}{ Cholinesterase inhibitors } \\
\hline Tariot et al. (2001) & Yes & Unclear & Yes & Yes & Yes & No \\
\hline Ballard et al. (2005) & Yes & Yes & Yes & Yes & Yes & Yes \\
\hline Holmes et al. (2007) & Unclear & Unclear & Yes & Yes & Yes & Yes \\
\hline \multicolumn{7}{|l|}{ Anticonvulsant } \\
\hline Tariot et al. (1998) & Unclear & Unclear & Yes & Yes & Yes & Yes \\
\hline $\begin{array}{l}\text { Porsteinsson et al. } \\
\text { (2001) }\end{array}$ & Unclear & Unclear & Yes & Yes & Yes & Yes \\
\hline Tariot et al. (2005) & Yes & Yes & Unclear & Yes & Yes & Yes \\
\hline Sommer et al. (2009) & Unclear & Unclear & Unclear & Yes & Yes & Yes \\
\hline \multicolumn{7}{|l|}{ Antidepressant } \\
\hline Gaber et al. (2001) & Unclear & Unclear & Yes & Unclear & Yes & Yes \\
\hline \multicolumn{7}{|l|}{ Other } \\
\hline Cantillon et al. (1996) & Unclear & Unclear & Yes & Yes & Yes & Unclear \\
\hline Kyomen et al. (1999) & Unclear & Yes & Unclear & Yes & Yes & Yes \\
\hline Hall et al. (2005) & Unclear & Unclear & Unclear & Yes & Yes & Yes \\
\hline Peskind et al. (2005) & Yes & Unclear & Yes & Yes & Yes & Yes \\
\hline Huertas et al. (2007) & Unclear & Unclear & Unclear & Yes & Yes & Yes \\
\hline Gehrman et al. (2009) & Unclear & Unclear & Yes & Unclear & Yes & Yes \\
\hline Wang et al. (2009) & Yes & Unclear & Yes & Yes & Yes & Yes \\
\hline
\end{tabular}

and psychosis (Sultzer et al., 2008). Although statistically significant results were observed in several studies in our review, clinically significant outcomes such as response rates or global clinical impression of change were only reported in a few studies.

Although there were few statistically significant differences noted on most safety outcomes, this is likely due to the limited power of many studies to detect adverse events associated with therapies. Existing meta-analyses and observational studies have however demonstrated major safety concerns with the use of atypical antipsychotics and other medications for NPS. Meta-analyses have demonstrated that atypical antipsychotics are associated with an increased risk of death (Schneider et al., 2005) with an odds ratio of 1.54, and an absolute risk difference of approximately $1 \%$ from studies conducted in LTC and other settings. Observational studies have also found an increased risk of mortality (Gill et al., 2007). Similarly, an increased risk of major cerebrovascular events associated with antipsychotics use has been observed in meta-analyses of RCTs (Herrmann and Lanctot, 2005), with a relative risk of 2.7 and an absolute risk difference of approximately $1 \%$. Other less serious, but more common side effects associated with atypical antipsychotics include increased rates of somnolence (Schneider et al., 2006a), falls (Hien Le et al., 2005), and fall-related injuries including hip fractures (Jalbert et al., 2010), which must also be monitored during therapy. There is also an increasing appreciation of the effects of atypical antipsychotics on cognitive and 
functional decline in older adults with dementia (Vigen et al., 2011).

There were relatively few studies that examined medications other than atypical antipsychotics. Some typical antipsychotics may also be effective for NPS (Schneider et al., 1990; Lanctot et al., 1998), although these medications are no more effective than atypical antipsychotics and are associated with higher rates of adverse events (De Deyn et al., 1999; Verhey et al., 2006; Tariot et al., 2006). The risk of death (Wang et al., 2005; Gill et al., 2007) and stroke (Herrmann et al., 2004; Gill et al., 2005) associated with typical antipsychotics is similar to or greater than the risk observed with atypical antipsychotics. There was only a single small study of antidepressants for NPS conducted in LTC, although there is growing interest in the use of antidepressants for this indication (Seitz et al., 2011). Recent RCTs of the antidepressant citalopram and escitalopram have indicated that these medications may be as effective as the antipsychotics risperidone (Pollock et al., 2007) or perphenazine (Pollock et al., 2002) and more effective than placebo (Pollock et al., 2002) in hospitalized inpatient populations. Importantly, the rates of adverse events with antidepressants may be less than that observed with antipsychotics (Pollock et al., 2007; Barak et al., 2011). However, serotonergic antidepressants have been associated with serious adverse events in older adults including falls (Vestergaard et al., 2006), fractures (Takkouche et al., 2007), bleeding (Andrade et al., 2010), and hyponatremia (Fabian et al., 2004). Some observational studies have also reported that antidepressants may be associated with an increased risk of death (Huybrechts et al., 2011) and stroke (Trifiro et al., 2010; Wu et al., 2011), although not all studies have confirmed these associations (Kales et al., 2007). The anticonvulsant carbamazepine demonstrated benefit in terms of reduction of agitation in a single small study conducted in LTC (Tariot et al., 1998) as well as two other small trials conducted outside of LTC (Cooney et al., 1996; Olin et al., 2001). Other medications reporting benefit were represented by single small studies and these agents may be considered for some individuals who do not tolerate or fail to respond to other treatments, although further research is needed to establish their efficacy and safety. Divalproex sodium was not effective at reducing NPS in studies included in our review (Porsteinsson et al., 2001; Tariot et al., 2005) and other studies have demonstrated that valproic acid may accelerate cognitive decline (Tariot et al., 2011) and, as such, these medications should be avoided in patients with NPS. Studies of cholinesterase inhibitors for the treatment of NPS did not find that these medications were effective in reducing NPS among patients with significant symptoms (Tariot et al., 2001; Ballard et al., 2005; Holmes et al., 2007), which has also been observed in trials conducted in community-based populations (Howard et al., 2007).

Although most of the trials in our review were between 6 and 12 weeks in length, in clinical practice antipsychotics are often prescribed for prolonged periods of time in LTC (Ballard et al., 2004; Ruths et al., 2004; Gill et al., 2007). The risk of adverse events associated with antipsychotics are greatest after initiating treatment (Gill et al., 2007), although chronic therapy is also associated with risks (Ballard et al., 2008). A placebo-controlled trial comparing continuation of antipsychotic therapy to placebo for LTC residents with NPS found that a decreased risk of mortality was associated with cessation of antipsychotics when compared with continued use (Ballard et al., 2009c). Discontinuation of antipsychotic therapy did not result in worsening of NPS for most individuals (Ballard et al., 2008). Additional RCTs have demonstrated that antipsychotics can be discontinued in the majority of individuals receiving chronic antipsychotic therapy without worsening of behavior (Cohen-Mansfield et al., 1999; van Reekum et al., 2002; Ballard et al., 2004; Ruths et al., 2004; 2008). Predictors of successful discontinuation of therapy include lower baseline severity of NPS (Ballard et al., 2004; 2008) and lower dosages of antipsychotics to achieve symptom control (van Reekum et al., 2002; Ruths et al., 2008).

There are some limitations to our review. One limitation relates to the method by which NPS were assessed, that being by retrospective questionnaire ratings of NPS as reported by nursing staff or other caregivers. Direct observations of behaviors would be considered the "gold standard" method for measuring NPS although studies have demonstrated that directly observed levels of agitation and questionnaire reported agitation are only moderately correlated (Cohen-Mansfield and Libin, 2004). However, direct measures of NPS are too labor intensive to be used as outcome measures in large clinical studies and questionnaire reports of behavior are more feasible to use in this setting. We only focused on published English-language studies and there are additional unpublished studies that have been identified (Schneider et al., 2006a), which may have introduced a publication bias in favor of studies showing benefits with medications (Turner et al., 2008). Many of the studies in our review were sponsored by pharmaceutical companies and studies that are sponsored by pharmaceutical companies are more likely to report outcomes in 
favor of the company's product than studies funded by other sources (Lexchin et al., 2003). Finally, due to the range of medications, outcome measures, and clinical populations, we did not undertake metaanalysis to quantitatively summarize the effects of medications.

Particular strengths of our review should be highlighted. First, we restricted our review to randomized controlled clinical trials to evaluate only the highest level of evidence. We also included only those studies conducted in LTC settings and so the results observed should be generalizable to other LTC populations. Our review also assessed the quality of included studies to identify potential sources of bias which may influence the internal validity of the primary studies. Finally, we undertook a detailed examination of the efficacy and safety of medications to allow clinicians to better appreciate and communicate the potential benefits and risks of various treatments.

\section{Conclusions}

The best supported evidence for management of NPS in LTC is for some atypical antipsychotics in particular risperidone, olanzapine, and aripiprazole. There are relatively few studies of other medications which have sufficient evidence base to support their use. However, the known risks of adverse events associated with antipsychotics and other psychotropic medications in LTC highlight the need for safe and effective alternatives to antipsychotics and existing pharmacological treatments. Nonpharmacological interventions should continue to be used as initial treatments for NPS where these are available, also taking into consideration patient and caregivers priorities. Further research into the comparative effectiveness of pharmacological treatments and non-pharmacological treatments is required to further understand the relative risks and benefits of treatments for NPS in LTC.

\section{Conflict of interest}

Dr. Herrmann has received grants or research funds from Sonexa, Sonafi, Aventis, and Lundbeck, honoraria from Pfizer and Lundbeck, and served as a consultant for Lundbeck.

\section{Description of authors' roles}

All authors made substantial contributions to the conception and design of the study and analysis and interpretation of data. Dr. Seitz and Ms. Brisbin and Ms. Rines contributed to the acquisition of studies and data extraction. All authors contributed to drafting the paper and revising it critically for intellectual content. All authors approved of the final version of the manuscript.

\section{Acknowledgments}

Dr. Seitz is supported by a Clinician Scientist Salary Support Award from Queen's University. This project was supported by a Canadian Institutes of Health Research Knowledge Synthesis Grant KRS\#103345 "Interventions for neuropsychiatric symptoms of dementia in long-term care: a systematic review."

\section{References}

Alexopoulos, G. S., Jeste, D. V., Chung, H., Carpenter, D., Ross, R. and Docherty, J. P. (2005). The expert consensus guideline series. Treatment of dementia and its behavioral disturbances. Introduction: methods, commentary, and summary. Postgraduate Medicine, Spec No, 6.

Andrade, C., Sandarsh, S., Chethan, K. B. and Nagesh, K. S. (2010). Serontonin reuptake inhibitor antidepressants and abnormal bleeding: a review for clinicians and reconsideration of mechanisms. Fournal of Clinical Psychiatry, 71, 1565-1575.

Ballard, C. and Howard, R. (2006). Neuroleptic drugs in dementia: benefits and harm. Nature Reviews Neuroscience, 7, 492-500.

Ballard, C. and Waite, J. (2006). The effectiveness of atypical antipsychotics for the treatment of aggression and psychosis in Alzheimer's disease. Cochrane Database of Systematic Reviews (Online), (1), CD003476.

Ballard, C. G. et al. (2004). A 3-month, randomized, placebo-controlled, neuroleptic discontinuation study in 100 people with dementia: the neuropsychiatric inventory median cutoff is a predictor of clinical outcome. Fournal of Clinical Psychiatry, 65, 114-119.

Ballard, C. et al. (2005). Quetiapine and rivastigmine and cognitive decline in Alzheimer's disease: randomised double blind placebo controlled trial. British Medical fournal, 330, 874.

Ballard, C. et al. (2008). A randomised, blinded, placebo-controlled trial in dementia patients continuing or stopping neuroleptics (The DART-AD Trial). PLoS Medicine, 5, 0587-0599.

Ballard, C., Corbett, A., Chitramohan, R. and Aarsland, D. (2009a). Management of agitation and aggression associated with Alzheimer's disease: controversies and possible solutions. Current Opinion in Psychiatry, 22, 532-540.

Ballard, C. et al. (2009b). Management of agitation and aggression associated with Alzheimer disease. Nature Reviews Neurology, 5, 245-255.

Ballard, C. et al. (2009c). The dementia antipsychotic withdrawal trial (DART-AD): long-term follow-up of a 
randomised placebo-controlled trial. The Lancet Neurology, 8, 151-157.

Barak, Y., Plopski, I., Tadger, S. and Paleacu, D. (2011). Escitalopram versus risperidone for the treatment of behavioral and psychotic symptoms associated with Alzheimer's disease: a randomized double-blind study. International Psychogeriatrics, 23, 1515-1519.

Barnes, R., Veith, R. and Okimoto, J. (1982). Efficacy of antipsychotic medications in behaviorally disturbed dementia patients. American fournal of Psychiatry, 139, 1170-1174.

Bharani, N. and Snowden, M. (2005). Evidence-based interventions for nursing home residents with dementia-related behavioral symptoms. Psychiatric Clinics of North America, 28, 985-1005.

Borson, S. and Raskind, M. A. (1997). Clinical features and pharmacologic treatment of behavioral symptoms of Alzheimer's disease. Neurology, 48, S17.

Brodaty, H. et al. (2003). A randomized placebo-controlled trial of risperidone for the treatment of aggression, agitation, and psychosis of dementia. Fournal of Clinical Psychiatry, 64, 134-143.

Burns, B. J., Wagner, H. R., Taube, J. E., Magaziner, J., Permutt, T. and Landerman, L. R. (1993). Mental health service use by the elderly in nursing homes. American Fournal of Public Health, 83, 331-337.

Canadian Coalition for Seniors' Mental Health (2006). National Guidelines for Seniors' Mental Health: The Assessment and Treatment of Mental Health Issues in Long Term Care Homes. Ontario: Canadian Coalition for Seniors' Mental Health.

Cantillon, M., Brunswick, R., Molina, D. and Bahro, $M$. (1996). Buspirone vs. haloperidol: a double-blind trial for agitation in a nursing home population with Alzheimer's disease. American fournal of Geriatric Psychiatry, 4, 263-267.

Cohen-Mansfield, J. and Jensen, B. (2008). Nursing home physicians' knowledge of and attitudes toward nonpharmacological interventions for treatment of behavioral disturbances associated with dementia. Fournal of the American Medical Directors Association, 9, 491-498.

Cohen-Mansfield, J. and Libin, A. (2004). Assessment of agitation in elderly patients with dementia: correlations between informant rating and direct observation. International Fournal of Geriatric Psychiatry, 19, 881889.

Cohen-Mansfield, J. and Mintzer, J. E. (2005). Time for change: the role of nonpharmacological interventions in treating behavior problems in nursing home residents with dementia. Alzheimer Disease and Associated Disorders, 19, 37-40.

Cohen-Mansfield, J., Lipson, S., Werner, P., Billig, N., Taylor, L. and Woosley, R. (1999). Withdrawal of haloperidol, thioridazine, and lorazepam in the nursing home. Archives of Internal Medicine, 159, 1733-1740.

Cohen-Mansfield, J., Thein, K., Marx, M. S. and Dakheel-Ali, D. (2012). What are the barriers to performing nonpharmacological interventions for behavioral symptoms in the nursing home? Fournal of the American Medical Directors Association, 13, 400-405.

Conn, D. K. (Ed.). (1992). Mental health issues in long-term care facilities. In Practical Psychiatry in the Nursing Home: A
Handbook for Staff. Ashland, OH: Hogrefe and Huber Publishers.

Conn, D. K. and Seitz, D. P. (2010). Advances in the treatment of psychiatric disorders in long-term care homes. Current Opinion in Psychiatry, 23, 516-521.

Cooney, C., Mortimer, A., Smith, A., Newton, K. and Wrigley, M. (1996). Carbamazepine use in aggressive behaviour associated with senile dementia. International Fournal of Geriatric Psychiatry, 11, 901-905.

De Deyn, P. P. et al. (1999). A randomized trial of risperidone, placebo, and haloperidol for behavioral symptoms of dementia. Neurology, 53, 946-955.

De Deyn, P. P. et al. (2004). Olanzapine versus placebo in the treatment of psychosis with or without associated behavioral disturbances in patients with Alzheimer's disease. International fournal of Geriatric Psychiatry, 19, 115-126.

Fabian, T. J. et al. (2004). Paroxetine-induced hyponatremia in older adults. Archives of Internal Medicine, 164, 327-332.

Fahey, T., Montgomery, A. A., Barnes, J. and Protheroe, J. (2003). Quality of care for elderly residents in nursing homes and elderly people living at home: controlled observational study. BMF, 326, 580-584.

Fontaine, C. S., Hynan, L. S., Koch, K., Martin-Cook, K., Svetlik, D. and Weiner, M. F. (2003). A double-blind comparison of olanzapine versus risperidone in the acute treatment of dementia-related behavioral disturbances in extended care facilities. Fournal of Clinical Psychiatry, 64, 726-730.

Gaber, S., Ronzoli, S., Bruno, A. and Biagi, A. (2001). Sertraline versus small doses of haloperidol in the treatment of agitated behavior in patients with dementia. Archives of Gerontology and Geriatrics, 33 (Suppl.), 159-162.

Gauthier, S., Cummings, J., Ballard, C., Brodaty, H., Grossberg, G., Robert, P. and Lyketsos, C. (2010). Management of behavioral problems in Alzheimer's disease. International Psychogeriatrics, 22, 346-372.

Gehrman, P. R., Connor, D. J., Martin, J. L., Shochat, T., Corey-Bloom, J. and Ancoli-Israel, S. (2009). Melatonin fails to improve sleep or agitation in double-blind randomized placebo-controlled trial of institutionalized patients with Alzheimer disease. American Fournal of Geriatric Psychiatry, 17, 166-169.

Gill, S. S. et al. (2005). Atypical antipsychotic drugs and risk of ischaemic stroke: population based retrospective cohort study. British Medical fournal, 330, 445.

Gill, S. S. et al. (2007). Antipsychotic drug use and mortality in older adults with dementia. Annals of Internal Medicine, 146, 775-786.

Gruber-Baldini, A. L., Boustani, M., Sloane, P. D. and Zimmerman, S. (2004). Behavioral symptoms in residential care/assisted living facilities: prevalence, risk factors, and medication management. Fournal of the American Geriatrics Society, 52, 1610-1617.

Hall, K. A., Keks, N. A. and O'Connor, D. W. (2005). Transdermal estrogen patches for aggressive behavior in male patients with dementia: a randomized, controlled trial. International Psychogeriatrics, 17, 165-178.

Herrmann, N. and Lanctot, K. L. (2005). Do atypical antipsychotics cause stroke? CNS Drugs, 19, 91-103.

Herrmann, N. and Lanctot, K. L. (2007). Pharmacologic management of neuropsychiatric symptoms of Alzheimer 
disease. Canadian fournal of Psychiatry (Revue canadienne de psychiatrie), 52, 630-646.

Herrmann, N., Mamdani, M. and Lanctot, K. L. (2004). Atypical antipsychotics and risk of cerebrovascular accidents. American fournal of Psychiatry, 161, 1113.

Herrmann, N., Gauthier, S. and Lysy, P. G. (2007). Clinical practice guidelines for severe Alzheimer's disease. Alzheimer's and Dementia, 3, 385-397.

Hien Le, T. T. et al. (2005). Aytypical antipsychotic medications and risk of falls in residents of aged care facilities. Fournal of the American Geriatrics Society, 53, 1290-1295.

Higgins, J. P. T. and Green, S. (2008). Cochrane Handbook for Systematic Reviews of Interventions. Chichester, UK: Wiley.

Holmes, C. et al. (2007). Risperidone and rivastigmine and agitated behaviour in severe Alzheimer's disease: a randomised double blind placebo controlled study. International fournal of Geriatric Psychiatry, 22, 380-381.

Howard, R. J. et al. (2007). Donepezil for the treatment of agitation in Alzheimer's disease. New England Fournal of Medicine, 357, 1382-1392.

Huertas, D. et al. (2007). Antiaggressive effect of cyproterone versus haloperidol in Alzheimer's disease: a randomized double-blind pilot study. Fournal of Clinical Psychiatry, 68, 439-444.

Huybrechts, K. F., Rothman, K. J., Silliman, R. A., Brookhart, M. A. and Schneeweiss, S. (2011). Risk of death and hospital admission for major medical events after initiation of psychotropic medications in older adults admitted to nursing homes. Canadian Medical Association fournal, 183, E411-E419.

Jalbert, J. J., Eaton, C. B., Miller, S. C. and Lapane, K. L. (2010). Antipsychotic use and the risk of hip fracture among older adults afflicted with dementia. Fournal of the American Medical Directors Association, 11, 120-127.

Kales, H. C. et al. (2007). Mortality risk in patients with dementia treated with antipsychotics versus other psychiatric medications. American fournal of Psychiatry, 164, 1568-1576.

Kales, H. C. et al. (2011). Trends in antipsychotic use in dementia 1999-2007. Archives of General Psychiatry, 68, 190-197.

Katz, I. R., Jeste, D. V., Mintzer, J. E., Clyde, C., Napolitano, J. and Brecher, M. (1999). Comparison of risperidone and placebo for psychosis and behavioral disturbances associated with dementia: a randomized, double-blind trial. Risperidone Study Group. Fournal of Clinical Psychiatry, 60, 107-115.

Kindermann, S. S., Dolder, C. R., Bailey, A., Katz, I. R. and Jeste, D. V. (2002). Pharmacological treatment of psychosis and agitation in elderly patients with dementia: four decades of experience. Drugs and Aging, 19, 257-276.

Konavalov, S., Muralee, S. and Tampi, R. R. (2007). Anticonvulsants for the treatment of behavioral and psychological symptoms of dementia: a literature review. International Psychogeriatrics, 20, 293-308.

Kozman, M. N., Wattis, J. and Curran, S. (2006). Pharmacological management of behavioral and psychological disturbance in dementia. Human Psychopharmacology: Clinical and Experimental, 21, 1-12.
Kyomen, H. H., Satlin, A., Hennen, J. and Wei, J. Y. (1999). Estrogen therapy and aggressive behavior in elderly patients with moderate-to-severe dementia. Results from a short-term, randomized, double-blind trial. American Fournal of Geriatric Psychiatry, 7, 339-348.

Lanctot, K. L. et al. (1998). Efficacy and safety of neuroleptics in behavioral disorders associated with dementia. Fournal of Clinical Psychiatry, 59, 550-561; quiz 562-563.

Larrayadieu, A. et al. (2011). Associated factors with antipsychotic use in assisted living facilities: a cross-sectional study in 4367 residents. Age and Ageing, 40, 368-375.

Lexchin, J., Bero, L. A., Djulbegovic, B. and Clark, O. (2003). Pharmaceutical industry sponsorship and research outcome and quality: systematic review. British Medical fournal, 326, 1167-1170.

Meeks, S. (1996). Psychological consultation to nursing homes: description of a six-year practice. Psychotherapy, 33, 19-29.

Mintzer, J. et al. (2006). Risperidone in the treatment of psychosis of Alzheimer disease: results from a prospective clinical trial. American fournal of Geriatric Psychiatry, 14, 280-291.

Mintzer, J. E. et al. (2007). Aripiprazole for the treatment of psychoses in institutionalized patients with Alzheimer dementia: a multicenter, randomized, double-blind, placebo-controlled assessment of three fixed doses. American fournal of Geriatric Psychiatry, 15, 918-931.

Moher, D., Liberati, A., Tetzlaff, J., Altman, D. G. and The Prisma Group. (2009). Preferred reporting items for systematic reviews and meta-analyses: the PRISMA statement. PLOS Medicine, 6, e1000097.

Nijk, R. M., Zuidema, S. U. and Koopmans, R. T. C. M. (2009). Prevalence and correlates of psychotropic drug use in Dutch nursing-home patients with dementia. International Psychogeriatrics, 21, 485-493.

Olin, J. T., Fox, L. S., Pawluczyk, S., Taggart, N. A. and Schneider, L. S. (2001). A pilot randomized trial of carbamazepine for behavioral symptoms in treatment-resistant outpatients with Alzheimer disease. American fournal of Geriatric Psychiatry, 9, 400-405.

Peskind, E. R. et al. (2005). Propranolol for disruptive behaviors in nursing home residents with probable or possible Alzheimer disease: a placebo-controlled study. Alzheimer Disease and Associated Disorders, 19, 23-28.

Pitkala, K. H., Laurila, J., Strandberg, T. and Tilvis, R. (2004). Behavioral symptoms and the administration of psychotropic drugs to aged patients with dementia in nursing homes and in acute geriatric wards. International Psychogeriatrics, 16, 61-74.

Pollock, B. G. et al. (2002). Comparison of citalopram, perphenazine, and placebo for the acute treatment of psychosis and behavioral disturbances in hospitalized, demented patients. The American fournal of Psychiatry, 159, 460-465.

Pollock, B. G. et al. (2007). A double-blind comparison of citalopram and risperidone for the treatment of behavioral and psychotic symptoms associated with dementia. American fournal of Geriatric Psychiatry, 15, 942-952. 
Porsteinsson, A. P. et al. (2001). Placebo-controlled study of divalproex sodium for agitation in dementia. American Fournal of Geriatric Psychiatry, 9, 58-66.

Rappaport, S. A., Marcus, R. N., Manos, G., McQuade, R. D. and Oren, D. A. (2009). A randomized, double-blind, placebo-controlled tolerability study of intramuscular aripiprazole in acutely agitated patients with Alzheimer's, vascular, or mixed dementia. Fournal of the American Medical Directors Association, 10, 21-27.

Reichman, W. E. et al. (1998). Psychiatric consultation in the nursing home: a survey of six states. American fournal of Geriatric Psychiatry, 6, 320-327.

Rochon, P. A. et al. (2007). Variation in nursing home antipsychotic prescribing rates. Archives of Internal Medicine, 167, 676-683.

Rochon, P. A. et al. (2008). Antipsychotic therapy and short-term serious events in older adults with dementia. Archives of Internal Medicine, 168, 1090-1096.

Ruths, S., Straand, J., Nygaard, H. A., Bjorvatn, B. and Pallesen, S. (2004). Effect of antipsychotic withdrawal on behavior and sleep/wake activity in nursing home residents with dementia: a randomized, placebo-controlled, double-blinded study the bergen district nursing home study. Fournal of the American Geriatrics Society, 52, 1737-1743.

Ruths, S., Straand, J., Nygaard, H. A. and Aarsland, D. (2008). Stopping antipsychotic drug therapy in demented nursing home patients: a randomized, placebo-controlled study - the Bergen District Nursing Home Study (BEDNURS). International fournal of Geriatric Psychiatry, 23, 889-895.

Saddichha, S. and Pandey, V. (2008). Alzheimer's and non-Alzheimer's dementia: a critical review of pharmacological and nonpharmacological strategies. American fournal of Alzheimer's Disease and Other Dementias, 23, 150-161.

Schneider, L. S., Dagerman, K. S. and Insel, P. (2005). Risk of death with atypical antipsychotic drug treatment for dementia: meta-analysis of randomized placebo-controlled trials. Fournal of the American Medical Association, 294, 1934-1943.

Schneider, L. S., Pollock, V. E. and Lyness, S. A. (1990) A metaanalysis of controlled trials of neuroleptic treatment in dementia. Fournal of the American Geriatrics Society, 38, 553-563.

Schneider, L. S., Dagerman, K. and Insel, P. S. (2006a). Efficacy and adverse effects of atypical antipsychotics for dementia: meta-analysis of randomized, placebo-controlled trials. American fournal of Geriatric Psychiatry, 14, 191-210.

Schneider, L. S. et al. (2006b). Effectiveness of atypical antipsychotic drugs in patients with Alzheimer's disease. New England fournal of Medicine, 355, 1525-1538.

Seitz, D. P., Gruneir, A., Conn, D. K. and Rochon, P. A. (2009). Cholinesterase inhibitor use in U.S. nursing homes: results from the National Nursing Home Survey. In American Association of Geriatric Psychiatry Annual Meeting. Honolulu, HA.

Seitz, D., Purandare, N. and Conn, D. (2010). Prevalence of psychiatric disorders among older adults in long-term care homes: a systematic review. International Psychogeriatrics, 22, 1025-1039.

Seitz, D., Adenuri, N., Gill, S. S., Gruneir, A., Herrmann, N. and Rochon, P. A. (2011).
Antidepressants for psychosis and agitation in dementia. Cochrane Database of Systematic Reviews, February 16, CD008191.

Seitz, D. P. et al. (2012). Efficacy and feasibility of non-pharmacological interventions for neuropsychiatric symptoms of dementia in long-term care: a systematic review. Fournal of the American Medical Directors Association, 13, 503-506.e2.

Selbaek, G., Kirkevold, O. and Engedal, K. (2007). The prevalence of psychiatric symptoms and behavioural disturbances and the use of psychotropic drugs in Norwegian nursing homes. International fournal of Geriatric Psychiatry, 22, 843-849.

Selbaek, G., Kirkevold, O. and Engedal, K. (2008). The course of psychiatric and behavioral symptoms and the use of psychotropic medication in patients with dementia in Norwegian nursing homes - a 12-month follow-up study. American fournal of Geriatric Psychiatry, 16, 528-536.

Sink, K. M., Holden, K. F. and Yaffe, K. (2005). Pharmacological treatment of neuropsychiatric symptoms of dementia: a review of the evidence. Fournal of the American Medical Association, 293, 596-608.

Snowden, M., Sato, K. and Roy-Byrne, P. (2003). Assessment and treatment of nursing home residents with depression or behavioral symptoms associated with dementia: a review of the literature. Fournal of the American Geriatrics Society, 51, 1305-1317.

Snowdon, J., Galanos, D. and Vaswani, D. (2011). Patterns of psychotropic medication use in nursing homes: surveys in Sydney, allowing comparisons over time and between countries. International Psychogeriatrics.

Sommer, O. H., Aga, O., Cvancarova, M., Olsen, I. C., Selbaek, G. and Engedal, K. (2009). Effect of oxcarbazepine in the treatment of agitation and aggression in severe dementia. Dementia and Geriatric Cognitive Disorders, 27, 155-163.

Street, J. S. et al. (2000). Olanzapine treatment of psychotic and behavioral symptoms in patients with Alzheimer disease in nursing care facilities: a double-blind, randomized, placebo-controlled trial. Archives of General Psychiatry, 57, 968-976.

Streim, J. E. et al. (2008). A randomized, double-blind, placebo-controlled study of aripiprazole for the treatment of psychosis in nursing home patients with Alzheimer disease. American fournal of Geriatric Psychiatry, 16, 537-550.

Sultzer, D. L. et al. (2008). Clinical symptom responses to atypical antipsychotic medications in Alzheimer's disease: phase 1 outcomes from the CATIE-AD effectiveness trial. American fournal of Psychiatry, 165, 844-854.

Sutor, B., Rummans, T. A. and Smith, G. E. (2001). Assessment and management of behavioral disturbances in nursing home patients with dementia. Mayo Clinic Proceedings, 76, 540-550.

Takkouche, B., Montes-Martinez, A., Gill, S. S. and Etminan, M. (2007). Psychotropic medications and the risk of fracture: a meta-analysis. Drug Safety, 30, 171184.

Tariot, P. N. et al. (1998). Efficacy and tolerability of carbamazepine for agitation and aggression in dementia. American fournal of Psychiatry, 155, 54-61.

Tariot, P. N. et al. (2001). A randomized, double-blind, placebo-controlled study of the efficacy and safety of donepezil in patients with Alzheimer's disease in the 
nursing home setting. Fournal of the American Geriatrics Society, 49, 1590-1599.

Tariot, P. N. et al. (2005). Divalproex sodium in nursing home residents with possible or probable Alzheimer disease complicated by agitation: a randomized, controlled trial. American fournal of Geriatric Psychiatry, 13, 942-949.

Tariot, P. N. et al. (2006). Quetiapine treatment of psychosis associated with dementia: a double-blind, randomized, placebo-controlled clinical trial. American fournal of Geriatric Psychiatry, 14, 767-776 [Erratum: (2006). American fournal of Geriatric Psychiatry, 14, 988].

Tariot, P. N. et al. (2011). Chronic divalproex sodium to attenuate agitation and clinical progression of Alzheimer disease. Archives of General Psychiatry, 68, 853-861.

Trifiro, G., Dieleman, J., Sen, E. F., Gambassi, G. and Sturkenboom, M. C. (2010). Risk of ischemic stroke associated with antidepressant drug use in elderly persons. Fournal of Clinical Psychopharmacology, 30, 252-258.

Turner, E. H., Matthews, A. M., Linardatos, E., Tell, R. A. and Rosenthal, R. (2008). Selective publication of antidepressant trials and its influence on apparent efficacy. New England fournal of Medicine, 358, 252-260.

Van Reekum, R., Clarke, D., Conn, D., Hermann, N., Eryavec, G., Cohen, T. and Ostrander, L. (2002). A randomized, placebo-controlled trial of the discontinuation of long-term antipsychotics in dementia. International Psychogeriatrics, 14, 197-210.

Verhey, F. R. J., Verkaaik, M. and Lousberg, R. (2006). Olanzapine versus haloperidol in the treatment of agitation in elderly patients with dementia: results of a randomized controlled double-blind trial. Dementia and Geriatric Cognitive Disorders, 21, 1-8.

Vestergaard, P., Rejnmark, L. and Mosekilde, L. (2006). Anxiolytics, sedatives, antidepressants, neuroleptics and the risk of fracture. Osteoporosis International, 17, 807-816.

Vigen, C. L. et al. (2011). Cognitive effects of atypical antipsychotic medications in patients with Alzheimer's disease: outcomes from CATIE-AD. American foumal of Psychiatry, 168, 831-839.

Wang, P. S. et al. (2005). Risk of death in elderly users of conventional vs. atypical antipsychotic medications. New England fournal of Medicine, 353, 2335-2341.

Wang, L. Y. et al. (2009). Prazosin for the treatment of behavioral symptoms in patients with Alzheimer disease with agitation and aggression. American fournal of Geriatric Psychiatry, 17, 744-751.

Wu, C. S., Wang, S. C., Cheng, Y. C. and Gau, S. S. (2011). Association of cerebrovascular events with antidepressant use: a case-crossover study. American Fournal of Psychiatry, 168, 511-521.

Zhong, K. X., Tariot, P. N., Mintzer, J., Minkwitz, M. C. and Devine, N. A. (2007). Quetiapine to treat agitation in dementia: a randomized, double-blind, placebo-controlled study. Current Alzheimer Research, 4, 81-93.

Zuidema, S., Koopmans, R. and Verhey, F. (2007). Prevalence and predictors of neuropsychiatric symptoms in cognitively impaired nursing home patients. Fournal of Geriatric Psychiatry and Neurology, 20, 41-49. 